\title{
Ethanol-Induced Increase of Agouti-Related Protein (AgRP) Immunoreactivity in the Arcuate Nucleus of the Hypothalamus of C57BL/6J, but not 129/SvJ, Inbred Mice
}

\author{
Inmaculada Cubero, Montserrat Navarro, Francisca Carvajal, Jose Manuel Lerma-Cabrera, \\ and Todd E. Thiele \\ Department of Neurociencia y Ciencias de la Salud (IC, FC, JML-C), University of Almeria, \\ Almeria, Spain; and Department of Psychology (MN, TET), University of North Carolina at Chapel \\ Hill, Chapel Hill, North Carolina
}

\begin{abstract}
Background-The melanocortin (MC) system is composed of peptides that are cleaved from the polypeptide precursor, pro-opiomelanocortin (POMC). Previous research has shown that MC receptor (MCR) agonists reduce, and MCR antagonists increase, ethanol consumption in rats and mice. Consistently, genetic deletion of the endogenous MCR antagonist, agouti-related protein (AgRP), causes reductions of ethanol-reinforced lever pressing and binge-like ethanol drinking in C57BL/6J mice. Ethanol also has direct effects on the central MC system, as chronic exposure to an ethanol-containing diet causes significant reductions of $\alpha$-melanocyte stimulating hormone ( $\alpha$ MSH) immunoreactivity in specific brain regions of Sprague-Dawley rats. Together, these observations suggest that the central MC system modulates neurobiological responses to ethanol. To further characterize the role of the MC system in responses to ethanol, here we compared $\mathrm{AgRP}$ and $\alpha$-MSH immunoreactivity in response to an acute injection of saline or ethanol between high ethanol drinking C57BL/6J mice and moderate ethanol drinking 129/SvJ mice.
\end{abstract}

Methods-Mice received an intraperitoneal (i.p.) injection of ethanol (1.5 g/kg or $3.5 \mathrm{~g} / \mathrm{kg}$; mixed in $0.9 \%$ saline) or an equivolume of $0.9 \%$ saline. Two hours after injection, animals were sacrificed and their brains were processed for AgRP and $\alpha$-MSH immunoreactivity.

Results-Results indicated that acute ethanol administration triggered a dose-dependent increase in AgRP immunoreactivity in the arcuate (ARC) of C57BL/6J mice, an effect that was not evident in the $129 / \mathrm{SvJ}$ strain. Although acute administration of ethanol did not influence $\alpha-\mathrm{MSH}$ immunoreactivity, C57BL/6J mice had significantly greater overall $\alpha-\mathrm{MSH}$ immunoreactivity in the ARC, dorsomedial, and lateral regions of the hypothalamus relative to the $129 / \mathrm{SvJ}$ strain. In contrast, C57BL/6J mice displayed significantly lower $\alpha-\mathrm{MSH}$ immunoreactivity in the medial amygdala.

Conclusions-The results show that acute ethanol exposure has direct effects on endogenous AgRP activity in ethanol preferring C57BL/6J mice. It is suggested that ethanol-induced increases in AgRP may be part of a positive feedback system that stimulates excessive binge-like ethanol drinking in C57BL/6J mice. Inherent differences in $\alpha-\mathrm{MSH}$ immunoreactivity may contribute to differences in neurobiological responses to ethanol that are characteristically observed between the C57BL/6J and 129/SvJ inbred strains of mice. 


\section{Keywords}

$\alpha$-MSH; AgRP; Immunoreactivity; 129/SvJ; C57BL/6J; Ethanol; Arcuate Nucleus; Medial

Amygdala

THE MELANOCORTIN (MC) system is composed of peptides that are cleaved from the polypeptide precursor pro-opiomelanocortin (POMC). Central MC peptides are produced by neurons within the hypothalamic arcuate (ARC) nucleus and the medulla (Dores et al., 1986; Jacobowitz and O'Donohue, 1978; O'Donohue and Dorsa, 1982), and include adrenocorticotropic hormone, $\alpha$-melanocyte stimulating hormone $(\alpha-\mathrm{MSH}), \beta-\mathrm{MSH}$, and $\gamma$ MSH (Hadley and Haskell-Luevano, 1999). Due to a lack of a critical dibasic site, $\beta$-MSH is not processed in rodent brain (Pritchard et al., 2002). In rodents, MC peptides act through 5 MC receptors (MC1R to MC5R) (Hadley and Haskell-Luevano, 1999). The MC3R and $\mathrm{MC} 4 \mathrm{R}$ are the primary MC receptors (MCR) expressed in the rodent brain (Alvaro et al., 1997). Agoutirelated protein (AgRP), a neuropeptide produced in the hypothalamus and cosecreted with neuropeptide $\mathrm{Y}$ in the same synaptic complexes as $\alpha$-MSH functions as a natural MCR antagonist (Shutter et al., 1997). More recent in vivo evidence suggests that AgRP may function as a MCR inverse agonist (Tolle and Low, 2008).

$\beta$-endorphin, an opioid peptide that is also cleaved from POMC and is co-expressed with $\alpha$ MSH in the brain (Bloch et al., 1979), modulates neurobiological responses to ethanol (Froehlich and Li, 1993; Gianoulakis, 2001; Rasmussen et al., 2002; Scanlon et al., 1992; Zhou et al., 2000) and opioid receptor antagonists reduce ethanol consumption (Gianoulakis, 2001). Interestingly, there appear to be a functional interaction between MC and opioid neuropeptides. For example, stimulation of MCRs block the antinociceptive effects of opioids, whereas MC4R antagonists enhance opioid antinociception (Ercil et al., 2005). It is therefore not surprising that evidence has emerged suggesting that $\mathrm{MC}$ neuropeptides also modulate neurobiological responses to ethanol. First, $\alpha$-MSH is expressed in brain regions implicated in ethanol's effects, including the striatum, nucleus accumbens (NAc), ventral teg-mental area (VTA), amygdala, hippocampus, and hypothalamus (Bloch et al., 1979; Dube et al., 1978; Jacobowitz and O'Donohue, 1978; O'Donohue and Jacobowitz, 1980; O'Donohue et al., 1979; Yamazoe et al., 1984). Second, rats selectively bred for high ethanol drinking (AA [Alko, Alcohol]) have low levels of MC3R in the shell of the NAc, but have high levels of MC3R and MC4R in various regions of the hypothalamus, when compared with low ethanol-drinking rats (Lindblom et al., 2002). Third, central infusion of the nonselective MCR agonist, melanotan-II (MTII) significantly reduced voluntary ethanol drinking in AA rats with an established history of ethanol intake (Ploj et al., 2002). Similarly, MTII-induced reduction of ethanol consumption was shown to be receptormediated and not associated with alterations of ethanol metabolism in C57BL/6J mice (Navarro et al., 2003). More recently, ventricular infusion of a selective MC4R agonist significantly reduced ethanol drinking, whereas ventricular infusion of the nonselective MCR antagonist AgRP-(83 to 132) significantly increased ethanol drinking, by C57BL/6J mice (Navarro et al., 2005). Consistent with pharmacological data, genetic deletion of endogenous AgRP reduced ethanol-reinforced lever pressing and binge-like ethanol drinking in C57BL/6J (Navarro et al., 2009). Ethanol also has direct effects on central MC activity. Thus, chronic exposure to ethanol significantly reduced (Navarro et al., 2008), while abstinence following chronic ethanol exposure increased (Kokare et al., 2008), endogenous $\alpha$-MSH immunoreactivity in specific brain regions of Sprague-Dawley rats.

The objective of this study was to further characterize the roles of endogenous AgRP and $\alpha$ MSH in the modulation of neurobiological responses to ethanol. Many genetically altered mouse lines, including MC3R-, MC4R-, and AgRP-deficient mice (Marsh et al., 1999; 
Navarro et al., 2005, 2009), were originally derived on a hybrid genetic background of the C57BL/6J inbred strain and 1 of the 129 substrains. Thus, assessing differences in AgRP and $\alpha$-MSH immunoreactivity between the C57BL/6J and a 129 strain would provide valuable informative for studies that examine ethanol-related phenotypes in MCR or AgRP knockout mice, or in other knockout mice which entail mutations that interact with the MC system. Furthermore, comparisons of inbred strains of mice is a useful first-step approach to identify neurochemical pathways that may modulate neurobiological responses to ethanol and ethanol intake (Bachtell et al., 2002; Hayes et al., 2005; Weitemier et al., 2005). Thus, here we compared brain AgRP and $\alpha$-MSH immunoreactivity between C57BL/6J and 129/ $\mathrm{SvJ}$ mice inbred strains that have been shown to exhibit different levels of ethanol consumption. C57BL $/ 6 \mathrm{~J}$ mice voluntarily consume $10 \mathrm{~g} / \mathrm{kg} / \mathrm{d}$ to $12 \mathrm{~g} / \mathrm{kg} / \mathrm{d}$ of ethanol when offered a $10 \%(\mathrm{v} / \mathrm{v})$ solution, while mice of the $129 / \mathrm{SvJ}$ strain consumes about half as much, or $5 \mathrm{~g} / \mathrm{kg} / \mathrm{d}$ to $6 \mathrm{~g} / \mathrm{kg} / \mathrm{d}$ of $10 \%$ ethanol (Belknap et al., 1993). Based on previous pharmacological and genetic observations, we predicted that these inbred strains would show differences in baseline and ethanol-induced AgRP and $\alpha-\mathrm{MSH}$ immunoreactivity in brain region implicated in neurobiological responses to ethanol.

\section{MATERIALS AND METHODS}

\section{Animals}

Male 129/SvJ and C57BL/6J inbred strains of mice (Jackson Laboratories, Bar Harbor, ME) weighed approximately $20 \mathrm{~g}$ to $25 \mathrm{~g}$ and were 6 to 8 weeks of age upon arrival. Mice were individually housed in polypropylene cages with wood-chip bedding and had ad libitum access to standard rodent chow (Teklad, Madison, WI) and water throughout the experiment. The colony room was maintained at approximately $22^{\circ} \mathrm{C}$ with a 12 hours: 12 hours, light:dark cycle. All procedures used in this study were in compliance with the National Institute of Health guidelines, and all protocols were approved by the University of North Carolina Institutional Animal Care and Use Committee. Body weight (g), water ( $\mathrm{ml} / \mathrm{kg} / 24$ $\mathrm{h}$ ), and food $(\mathrm{g} / \mathrm{kg} / 24 \mathrm{~h}$ ) consumption were collected for 1 week prior to the experiment and average baseline measures were calculated for each strain of inbred mice.

\section{Acute Ethanol Administration}

On the test day, mice were weighed, and water and food were removed from each cage. Then, mice were divided into 3 groups based on body weight, and given a single intraperitoneal (i.p.) injection of ethanol $(1.5 \mathrm{~g} / \mathrm{kg}$ or $3.5 \mathrm{~g} / \mathrm{kg}, 7.5 \mathrm{ml} / \mathrm{kg}$ and $17.5 \mathrm{ml} / \mathrm{kg}$, respectively; $20 \%$ [w/v] mixed in $0.9 \%$ saline $)$ or an equivolume of $0.9 \%$ saline $(17.5 \mathrm{ml} /$ $\mathrm{kg}$ ). Mice were then returned to their homecage immediately after the injection where they remained until perfusion procedures. As $\alpha-\mathrm{MSH}$ and AgRP have been implicated in feeding behaviors (Sainsbury et al., 2002), procedures were carried out during the animals' light cycle, a time of day in which feeding behavior in mice is low. Injections began 2 hours into the light cycle, and were staggered (counterbalanced by strain and injection condition) so that all mice were perfused exactly 2 hours after injection. Another set of naive C57BL/6J and $129 / \mathrm{SvJ}$ mice were given i.p. injection of a $1.5 \mathrm{~g} / \mathrm{kg}$ or $3.5 \mathrm{~g} / \mathrm{kg}$ dose of ethanol, and blood samples were collected 2 hours later to assure that ethanol-induced differences in immunohistochemistry (IHC) between strains were not associated with strain differences in blood ethanol concentrations (BECs). Approximately $10 \mu \mathrm{l}$ of blood was collected from the tail vein of each mouse, samples were centrifuged, and $5 \mu \mathrm{l}$ of plasma from each sample was analyzed for BECs measured in mg/dl (Analox Instruments, Lunenburg, MA).

\section{Perfusions, Brain Preparation, and Immunohistochemistry}

Two hours after ethanol or saline injection, mice were injected with a cocktail of ketamine $(117 \mathrm{mg} / \mathrm{kg})$ and xylazine $(7.92 \mathrm{mg} / \mathrm{kg})$ and then transcardially perfused for 10 minutes with 
$0.1 \mathrm{mM}$ phosphate-buffered saline (PBS; $\mathrm{pH}$ 7.4) followed by 4\% paraformaldehyde in phosphate buffer. The 2 hours postinjection perfusion time was chosen because we have previously found treatment-induced differences in protein at this time interval (Thiele et al., 1997, 1998a, 2000). All perfusions were completed within a 5-hour window of time. The brains were collected and postfixed in paraformaldehyde for 24 hours at $4{ }^{\circ} \mathrm{C}$, at which point they were transferred to PBS. Brains were cut using a vibrotome into $40 \mu \mathrm{m}$ sections and were then stored in PBS. IHC procedures were based on those routinely used in our laboratory (Hayes et al., 2005; Thiele et al., 1996, 1997, 1998a,b, 2000). Sections were evenly divided into 2 sets (every-other section) for processing with $\alpha$-MSH or AgRP antibodies. After rinsing in fresh PBS 4 times (10 minutes each), tissue sections were blocked in $10 \%$ rabbit serum (for $\alpha-\mathrm{MSH}$ ) or $10 \%$ goat serum (for AgRP) and $0.1 \%$ triton$\mathrm{X}-100$ in PBS for 1 hour. Sections were then transferred to fresh PBS containing primary sheep anti- $\alpha-\mathrm{MSH}$ (Millipore, Billerica, MA; $1: 10,000$ ) or primary rabbit anti-AgRP (Phoenix Pharmaceuticals, Inc., Burlingame, CA; 1:4,000) for 3 days at $4^{\circ} \mathrm{C}$. As a control to determine if staining required the presence of the primary antibodies, some sections were run through the assay without primary antibody ( $\alpha-\mathrm{MSH}$ or AgRP). In each assay described below, tissue processed without the primary antibody failed to show staining that was evident in tissue processed with primary antibody. After the 3 days of incubation, the sections were rinsed 4 times and then processed with Vectastain Elite kits (Vector Labs, Burlingame, CA) as per the manufacturer's instructions for standard ABC/HRP/ diaminobenzidinebased IHC. The sections processed for $\alpha-\mathrm{MSH}$ or AgRP were visualized by reacting the sections with a 3,3-diaminobenzidine tetrahydrochloride (DAB; Polysciences, Inc., Warrington, MA) reaction solution containing $0.05 \%$ DAB, $0.005 \%$ cobalt, $0.007 \%$ nickel ammonium sulfate, and $0.006 \%$ hydrogen peroxide. All sections were mounted on glass slides, air-dried overnight, and cover slipped for viewing. Digital images of $\alpha$-MSH and AgRP IHC were obtained on a Nikon E400 microscope equipped with a Nikon Digital Sight DS-U1 digital camera run with Nikon-provided software. For analysis, great care was taken to match sections through the same region of brain and at the same level using anatomic landmarks with the aid of a mouse stereotaxic atlas (Franklin and Paxinos, 1997). Densitometric procedures were used to assess protein levels. Flat-field corrected digital pictures (8-bit grayscale) were taken using the Digital Sight DS-U1 camera and density of staining was analyzed using Image $\mathbf{J}$ software (Image $\mathbf{J}$; National Institute of Health, Bethesda, MD) by calculating the percent of the total area examined that showed signal (cell bodies and processes) relative to a subthreshold background. The size of the areas that were analyzed was the same between animals and groups. The subthreshold level for the images was set in such a way that any area without an experimenter-defined level of staining (determined by terminal- and/or soma-positive regions) was given a value of zero. Within each region, the same subthreshold level was used for each slice that was scored. Data from each brain region in an animal were calculated by taking the average counts from 2 brain slices. Data from each slice were calculated by taking the average counts from the left and right sides of the brain at the specific brain region of interest. For each brain region, photographs were taken at approximately the medial area of the structure (with respect to the rostral-caudal axis) for each of the 2 brain slices that were scored. In all cases, quantification of IHC data was conducted by an experimenter that was blinded to group identity. We quantified $\alpha$-MSH immunoreactivity in regions of the hypothalamus (the ARC, dorsomedial $[\mathrm{DMH}]$, and lateral $[\mathrm{LH}]$ regions) and the medial amygdala (MA) regions in which we found robust $\alpha$-MSH staining and which have been implicated in neurobiological responses to ethanol and other drugs of abuse (Aston-Jones et al., 2009; Cannella et al., 2009; DiLeone et al., 2003; Doron et al., 2006; Harris and Aston-Jones, 2006; Hunt and McGregor, 1998; Koob, 2003). Consistent with our previous findings (Navarro et al., 2008), AgRP immunoreactivity was observed primarily in the ARC. 


\section{Data Analyses}

All data collected in this study are presented as mean \pm SEM and differences between groups were analyzed using analysis of variance (ANOVA). One-way ANOVAs were performed on baseline body weight, food intake, and water consumption data. Independent twoway, $2 \times 3$ (strain $\times$ dose) ANOVAs were performed on IHC data collected from each brain region and on BEC data. Sample sizes vary in IHC analyses below as appropriate representative sections through target brain regions were not available in some cases. When significant main effects or interactions were found, post hoc analyses were conducted using Newman-Keuls tests. To control for the increased likelihood of Type 1 errors with multiple comparisons, the level of significance was set at $p<0.0125$ for analyses involving $\alpha$-MSH immunoreactivity data in the 4 brain regions examined, consistent with a Bonferroni correction. For all other analyses, the level of significance was set at $p<0.05$.

\section{RESULTS}

\section{Strain Comparisons of Body Weight, Food and Water Intake, and Blood Ethanol Levels}

Because $\alpha$-MSH and AgRP have been implicated in food intake and body weight regulation (Sainsbury et al., 2002), we determined if there were differences between C57BL/6J and $129 / \mathrm{SvJ}$ mice in body weight, food intake, and water drinking. The C57BL/6J mice $(n=25)$ and $129 / \mathrm{SvJ}$ mice $(n=25)$ did not differ significantly in average body weight $([\mathrm{F}(1,48)=$ $0.2, p>0.05] ; 20.6 \pm 0.14 \mathrm{~g}$ and $20.4 \pm 0.14 \mathrm{~g}$, respectively), food intake $([F(1,48)=0.4, p$ $>0.05] ; 4.5 \pm 0.14 \mathrm{~g} / \mathrm{d}$ and $4.6 \pm 0.14 \mathrm{~g} / \mathrm{d}$, respectively), or water drinking $[\mathrm{F}(1,48)=0.2, p$ $>0.05$ ]; $5.2 \pm 0.14 \mathrm{ml} / \mathrm{d}$ and $5.1 \pm 0.14 \mathrm{ml} / \mathrm{d}$, respectively). Additionally, C57BL/6J ( $n=7$ per dose condition) and $129 / \mathrm{SvJ}$ ( $n=6$ or 7 for the $1.5 \mathrm{~g} / \mathrm{kg}$ and $3.5 \mathrm{~g} / \mathrm{kg}$ doses of ethanol, respectively) mice did not differ significantly in BECs 2 hours following injection of a $1.5 \mathrm{~g} /$ $\mathrm{kg}(51.11 \pm 4.48 \mathrm{mg} / \mathrm{dl}$ and $71.03 \pm 4.49 \mathrm{mg} / \mathrm{dl}$, respectively $)$ or a $3.5 \mathrm{~g} / \mathrm{kg}(273.12 \pm 3.51$ $\mathrm{mg} / \mathrm{dl}$ and $277.96 \pm 16.36 \mathrm{mg} / \mathrm{dl}$, respectively) dose of ethanol. A two-way ANOVA performed on BEC data showed a significant main effect of ethanol dose $[F(1,23)=538.02$, $p<0.05]$ but neither the strain main effect $[F(1,23)=1.79, p>0.05]$ nor interaction effect $[F(1,23)=0.66, p>0.05]$ were statistically significant.

\section{AgRP IHC in the Arcuate Nucleus Following Saline or Ethanol Injection}

Figure 1 shows data representing the average densities of AgRP immunoreactivity in the ARC of 129/SvJ and C57BL/6J mice given i.p. injection of saline $(n=6$ and 4, respectively), a $1.5 \mathrm{~g} / \mathrm{kg}$ dose of ethanol ( $n=7$ and 4 , respectively) or a $3.5 \mathrm{~g} / \mathrm{kg}$ dose of ethanol ( $n=5$ and 7, respectively), and representative photomicrographs of AgRP immunoreactivity in the ARC of $129 / \mathrm{SvJ}$ and C57BL/6J mice are presented in Fig. 2. A twoway ANOVA performed on this data set showed a statistically significant main effect of mouse strain $[F(1,27)=14.15, p<0.05]$ and a significant dose $\times$ mouse strain interaction $[F(2,27)=5.0, p<0.05]$, but the dose main effect was not statistically significant $[F(1,27)$ $=1.5, p>0.05]$. Post hoc Newman-Keuls tests showed that C57BL/6J mice exhibited a dose-dependent increase in AgRP immunoreactivity that was not evident in 129/SvJ mice.

\section{a-MSH IHC in Regions of the Hypothalamus and MA Following Saline or Ethanol Injection}

Arcuate Nucleus-Figure $3 A$ shows data representing the average densities of $\alpha$-MSH immunoreactivity in the ARC of $129 / \mathrm{SvJ}$ and C57BL/6J mice given i.p. injection of saline ( $n=4 /$ strain), a $1.5 \mathrm{~g} / \mathrm{kg}$ dose of ethanol ( $n=8$ and 5 , respectively) or a $3.5 \mathrm{~g} / \mathrm{kg}$ dose of ethanol ( $n=6$ and 7, respectively), and representative photomicrographs of $\alpha$-MSH immunoreactivity in the ARC of $129 / \mathrm{SvJ}$ and $\mathrm{C} 57 \mathrm{BL} / 6 \mathrm{~J}$ mice are presented in Fig. $4 A, E$, respectively. A two-way ANOVA performed on these data revealed a significant main effect of mouse strain $[F(1,28)=7.4, p<0.0125]$. Neither the dose effect $[F(2,28)=0.6, p>$ 
$0.0125]$ nor the dose $\times$ strain interaction $[F(2,28)=0.4, p>0.0125]$ attained statistical significance.

Lateral Hypothalamus-Figure 3B shows data representing the average densities of $\alpha$ MSH immunoreactivity in the LH of $129 / \mathrm{SvJ}$ and C57BL/6J mice given i.p. injection of saline ( $n=8 / \mathrm{strain})$, a $1.5 \mathrm{~g} / \mathrm{kg}$ dose of ethanol ( $n=8 / \mathrm{strain})$ or a $3.5 \mathrm{~g} / \mathrm{kg}$ dose of ethanol ( $n$ $=8$ and 9 , respectively), and representative photomicrographs of $\alpha-\mathrm{MSH}$ immunoreactivity in the LH of 129/SvJ and C57BL/6J mice are presented in Fig. 4B,F, respectively. A twoway ANOVA performed on this data set showed a significant main effect of mouse strains $[F(1,43)=39.2, p<0.0125]$. The dose main effect $[F(2,43)=0.4, p>0.0125]$ and the interaction effect $[F(2,43)=0.7, p>0.0125]$ were not statistically significant.

Dorsomedial Hypothalamus-Figure 3C shows data representing the average densities of $\alpha$-MSH immunoreactivity in the DMH of $129 / \mathrm{SvJ}$ and C57BL/6J mice given i.p. injection of saline ( $n=7 / \mathrm{strain}$ ), a $1.5 \mathrm{~g} / \mathrm{kg}$ dose of ethanol ( $n=6$ and 8 , respectively) or a $3.5 \mathrm{~g} / \mathrm{kg}$ dose of ethanol ( $n=7$ and 8 , respectively), and representative photomicrographs of $\alpha$-MSH immunoreactivity in the DMH of $129 / \mathrm{SvJ}$ and C57BL/6J mice are presented in Fig. 4C, $G$, respectively. A two-way ANOVA performed on these data showed a statistically significant main effect of mouse strains $[F(1,37)=10.7, p<0.0125]$, but neither the dose $[F(2,37)=$ $0.7, p>0.0125]$ nor the interaction $[F(2,37)=0.8, p>0.0125]$ effects were statistically significant. Taken together, these results show that hypothalamic $\alpha-\mathrm{MSH}$ immunoreactivity is significantly higher in the C57BL/6J strain relative to $129 / \mathrm{SvJ}$ strain of mice.

Immunoreactivity of $\boldsymbol{\alpha}-\mathbf{M S H}$ in the MA-Figure $3 D$ shows data representing the average densities of $\alpha$-MSH immunoreactivity in the MA of $129 / \mathrm{SvJ}$ and C57BL/6J given i.p. injection of saline ( $n=8 / \mathrm{strain})$, a $1.5 \mathrm{~g} / \mathrm{kg}$ dose of ethanol ( $n=8 / \mathrm{strain})$ or a $3.5 \mathrm{~g} / \mathrm{kg}$ dose of ethanol ( $n=9 /$ strain), and representative photomicrographs of $\alpha$-MSH immunoreactivity in the MA of $129 / \mathrm{SvJ}$ and C57BL/6J mice are presented in Fig. 4D, H, respectively. As above, a two-way ANOVA performed on these data revealed a significant main effect of mouse strain $[F(1,44)=7.85, p<0.0125]$, but neither the dose $[F(2,44)=$ $1.9, p>0.0125]$ nor interaction $[F(2,44)=0.2, p>0.0125]$ effects achieved statistical significance. In contrast to the hypothalamic regions examined, $\alpha$-MSH immunoreactivity in the MA was significantly lower in C57BL/6J mice relative to $129 / \mathrm{SvJ}$ mice.

\section{DISCUSSION}

The most important observation is the present work is that acute administration of a $3.5 \mathrm{~g} / \mathrm{kg}$ dose of ethanol caused a significant increase in AgRP immunoreactivity in the ARC of C57BL/6J mice, an effect that was not evident in 129/SvJ mice. Strain differences in AgRP immunoreactivity are not likely secondary to strain differences in ethanol metabolism as C57BL/6J and 129/SvJ mice showed similar BECs 2 hours following injection of a $3.5 \mathrm{~g} / \mathrm{kg}$ dose of ethanol. Additionally, since there were no strain differences in body weight, absolute dosing volume is also not an explanation for strain differences in ethanol-induced AgRP immunoreactivity. Since AgRP plays a role in the modulation of caloric intake, it might be argued that the extra calories associated with ethanol administration were the cause of increased AgRP immunoreactivity in mice injected with the $3.5 \mathrm{~g} / \mathrm{kg}$ dose. However, reduced caloric intake stemming from fasting is associated with increased AgRP immunoreactivity in the hypothalamus of rats, mice, and sheep (Dunbar et al., 2005; Fetissov et al., 2005; Wagner et al., 2004). In contrast, increasing caloric load (Chang et al., 2005; Ziotopoulou et al., 2000) and hyperphagia in obese tub/tub mice (Backberg et al., 2004) are associated with decreased AgRP expression. Taken together, these previous findings make it unlikely that increased AgRP immunoreactivity in the present report was caused by the calories inherent in ethanol. 
With IHC procedures, increased immunoreactivity in response to ethanol exposure could indicate that ethanol facilitates normal signaling via increased production of AgRP. Alternatively, ethanol-induced increases of AgRP immunoreactivity could reflect blunted AgRP signaling, via an attenuation of release and/or augmentation of AgRP re-uptake into presynaptic terminals. While either ethanol-induced increases or decreases in AgRP signaling are possible, the most significant observation in the present work is that ethanol appears to have direct affects on central AgRP activity. This being said, based on previous observations that have implicated AgRP signaling in the modulation of ethanol consumption, we suggest that ethanol-induced increases of AgRP immunoreactivity likely reflect an increase of AgRP signaling. First, central infusion of the AgRP-(83 to 132) fragment increases (Navarro et al., 2005), while genetic deletion of AgRP reduces (Navarro et al., 2009), ethanol self-administration by C57BL/6J mice. Second, C57BL/6J mice show twice the level of ethanol drinking relative to $129 / \mathrm{SvJ}$ mice when offered a $10 \%$ ethanol solution (Belknap et al., 1993) and here we found that only C57BL/6J mice showed ethanolinduced increases of AgRP. While it is not completely clear if ethanol drinking promotes increases of AgRP immunoreactivity in C57BL/6J mice or if ethanol-induced AgRP immunoreactivity contributes to the high level of ethanol drinking characteristic of this strain, an interesting possibility is that ethanol-induced increase of AgRP signaling is part of mechanism that involves a positive feedback loop, such that ethanol intake stimulates AgRP which in turn promotes further excessive binge-like drinking. In fact, AgRP immunoreactivity has been identified in brain regions implicated in ethanol consumption, including the VTA, NAc, amygdala, bed nucleus of the stria terminalis, and lateral septum (Bagnol et al., 1999), and we have recently shown that AgRP positively modulates bingelike ethanol drinking in C57BL/6J mice (Navarro et al., 2009). Such a positive feedback loop has also been proposed for the neuropeptide galanin. As with AgRP, ethanol stimulates hypothalamic galanin activity and central galanin administration promotes ethanol consumption (Lewis et al., 2005; Schneider et al., 2007). It will be important in future work to determine if $\mathrm{C} 57 \mathrm{BL} / 6 \mathrm{~J}$ mice show increased $\mathrm{AgRP}$ immunoreactivity following a bout of binge-like ethanol drinking. It should be noted that because C57BL/6J and 129/SvJ mice have also been reported to show differences in other ethanol-related phenotypes, such as ethanol-induced sedation (Homanics et al., 1999), AgRP signaling may be involved with any number of neurobiological responses to ethanol that differ between these strains.

The second observation of interest in the present report is that there were region-specific differences in $\alpha-\mathrm{MSH}$ immunoreactivity between strains with C57BL/6J mice showing significantly higher $\alpha-\mathrm{MSH}$ immunoreactivity in regions of the hypothalamus and lower $\alpha$ MSH immunoreactivity in the MA relative to $129 / \mathrm{SvJ}$ mice. Additionally, the significant main effect of mouse strain in AgRP immunoreactivity indicates that C57BL/6J mice also display a general increase of AgRP in the ARC when compared with $129 / \mathrm{SvJ}$ mice. While $\alpha-\mathrm{MSH}$ and AgRP have been implicated in food intake and body weight regulation (Sainsbury et al., 2002), the present observations that C57BL/6J and 129/SvJ mice showed statistically similar food intake and body weight suggests that strain differences in $\alpha-\mathrm{MSH}$ and AgRP immunoreactivity are not likely related to strain differences in feeding and energy homeostasis. Because C57BL/6J mice drink on average twice as much $10 \%$ ethanol as 129 / SvJ mice (Belknap et al., 1993) and are less sensitive to the sedative/hypnotic effects of ethanol (Homanics et al., 1999), and in light of the gowning evidence suggesting a role for $\alpha$-MSH and AgRP ethanol-related phenotypes (Kokare et al., 2008; Navarro et al., 2003, 2005, 2008, 2009; Ploj et al., 2002), it is tempting to speculate that the strain differences in $\alpha-\mathrm{MSH}$ and AgRP immunoreactivity contribute to the differences in neurobiological responses to ethanol that are characteristically observed between C57BL/6J and $129 / \mathrm{SvJ}$ mice. However, given that these peptides modulate a diverse set of neurobiological functions, additional work is needed to determine if strain differences in $\alpha-\mathrm{MSH}$ and AgRP 
contribute to C57BL/6J and 129/SvJ strain differences in neurobiological responses to ethanol.

Previous research has shown that chronic exposure to ethanol significantly reduced (Navarro et al., 2008), while abstinence following chronic ethanol exposure increased (Kokare et al., 2008) endogenous $\alpha$-MSH immunoreactivity in specific brain regions of Sprague-Dawley rats. The absence of an effect of acute ethanol administration on $\alpha$-MSH immunoreactivity in the present work may suggest that ethanol-induced changes in $\alpha$-MSH immunoreactivity gradually emerge with chronic exposure. However, an acute i.p. injection of a $2.0 \mathrm{~g} / \mathrm{kg}$ dose of ethanol was reported to decrease $\alpha$-MSH immunoreactivity in regions of the hypothalamus and amygdala of rats (Kokare et al., 2008), raising the possibility that there are species (mice vs. rats) differences in $\alpha$-MSH immunoreactivity in response to acute ethanol injections. However, it should be noted that in the rat study (Kokare et al., 2008), animals injected with ethanol were compared with a group of rats that had consumed a nutritionally balanced liquid diet (in place of food) for 15 days, which raises the possibility that group differences in $\alpha$-MSH immunoreactivity were related to factors other than acute ethanol exposure, including differences in caloric intake and a host of other procedural differences. Nonetheless, before ruling out a role for endogenous $\alpha-\mathrm{MSH}$ in the modulation ethanol's acute effects, further characterization is required (e.g., in other strains or species, with additional doses of ethanol, following ethanol self-administration, and with other techniques for assessing protein levels such as Western blotting).

One caveat that must be considered is that stress associated with i.p. injection of ethanol produced nonspecific effects on $\alpha$-MSH and/or AgRP immunoreactivity. In fact, stress exposure increases $\alpha$-MSH release into the blood-stream (Goudreau et al., 1993; Liu et al., 2007) and blunts central AgRP signaling (Kas et al., 2005). While we did not observe ethanol-induced alterations of $\alpha$-MSH immunoreactivity, possible stress-induced increases of $\alpha$-MSH immunoreactivity may have masked the attenuating effects of ethanol on $\alpha$-MSH (Navarro et al., 2008). However, it is unlikely that the stress associated with ethanol injections accounts for the strain differences observed with $\alpha$-MSH immunoreactivity data as there were no significant dose by strain interaction effects (that is, strain differences were evident regardless of saline or ethanol treatment). Furthermore, since foot shock-induced stress decreases AgRP mRNA in the ARC which is associated with evidence of blunted AgRP release (Kas et al., 2005), ethanol-induced increases of AgRP immunoreactivity in the $\mathrm{ARC}$ are likely not related to stress. Finally, while the effects of a ketamine/xylazine (K/X) anesthetic on $\alpha$-MSH or AgRP immunoreactivity have not been assessed, previous work has revealed that rats anesthetized with $\mathrm{K} / \mathrm{X}$ failed to show increased c-Fos immunoreactivity in all but 1 brain region examined relative to awake rats when brains were collected 2 hours after drug administration. Halothane anesthesia, on the other hand, induced elevations of cFos immunoreactivity in all the 7 brain regions that were examined (Roda et al., 2004). In light of these observations with c-Fos immunoreactivity, we believe that it is unlikely that $\mathrm{K} /$ $\mathrm{X}$ administration influenced $\alpha-\mathrm{MSH}$ or AgRP immunoreactivity in the present report.

In conclusion, the present report provides novel evidence that acute exposure to ethanol induces a dose-dependent increase in AgRP immunoreactivity in the ARC of ethanol preferring C57BL/6J mice, but not in moderate ethanol drinking 129/SvJ mice. This observation suggests that endogenous AgRP signaling may contribute to some of the differences in neurobiological responses to ethanol between these strains, including ethanol consumption and/or ethanol-induced sedation. It will be important in future studies to determine if excessive binge-like ethanol consumption in C57BL/6J mice also promotes increases of AgRP immuno-reactivity. Finally, while previous work shows that changes of endogenous $\alpha-\mathrm{MSH}$ immunoreactivity are present following chronic ethanol exposure and ethanol withdrawal, the current observations failed to show changes in $\alpha$-MSH 
immunoreactivity following acute ethanol administration. Taken together, an interesting possibility is that changes in $\alpha$-MSH signaling over the course of long-term ethanol exposure contributes to ethanol dependence, whereas increases of AgRP signaling in response to acute ethanol administration contributes to the immediate neurobiological responses to ethanol, including those that modulate the reinforcing properties of ethanol and binge-like drinking. Thus, compounds which target MCRs may prove to have therapeutic value in the treatment excessive ethanol consumption and/or the symptoms associated with ethanol dependence and withdrawal.

\section{Acknowledgments}

This work was supported by NIH grants AA013573 and AA015148, Department of Defense grants W81XWH-06-1-0158 and W81XWH-09-1-0293, and MEC grants (Spain) SEJ2006-03629, "Programa Salvador Madariaga 2006" and J. A., grant CTS1350. We thank Dr. Darin Knapp for his expert advice on photographing and quantifying immunoreactivity data.

\section{REFERENCES}

Alvaro JD, Tatro JB, Duman RS. Melanocortins and opiate addiction. Life Sci. 1997; 61:1-9. [PubMed: 9200663]

Aston-Jones G, Smith RJ, Moorman DE, Richardson KA. Role of lateral hypothalamic orexin neurons in reward processing and addiction. Neuropharmacology. 2009; 56(Suppl 1):112-121. [PubMed: 18655797]

Bachtell RK, Tsivkovskaia NO, Ryabinin AE. Strain differences in urocortin expression in the Edinger-Westphal nucleus and its relation to alcohol-induced hypothermia. Neuroscience. 2002; 113:421-434. [PubMed: 12127099]

Backberg M, Madjid N, Ogren SO, Meister B. Down-regulated expression of agouti-related protein (AGRP) mRNA in the hypothalamic arcuate nucleus of hyperphagic and obese tub/tub mice. BrainRes Mol Brain Res. 2004; 125:129-139.

Bagnol D, Lu XY, Kaelin CB, Day HE, Ollmann M, Gantz I, Akil H, Barsh GS, Watson SJ. Anatomy of an endogenous antagonist: relationship between Agouti-related protein and proopiomelanocortin in brain. J Neurosci. 1999; 19:RC26. [PubMed: 10479719]

Belknap JK, Crabbe JC, Young ER. Voluntary consumption of ethanol in 15 inbred mouse strains. Psychopharmacology. 1993; 112:503-510. [PubMed: 7871064]

Bloch B, Bugnon C, Fellmann D, Lenys D, Gouget A. Neurons of the rat hypothalamus reactive with antisera against endorphins, ACTH, MSH and beta-LPH. Cell Tissue Res. 1979; 204:1-15. [PubMed: 230904]

Cannella N, Economidou D, Kallupi M, Stopponi S, Heilig M, Massi M, Ciccocioppo R. Persistent increase of alcohol-seeking evoked by neuropeptide $\mathrm{S}$ : an effect mediated by the hypothalamic hypocretin system. Neuropsychopharmacology. 2009; 34:2125-2134. [PubMed: 19322167]

Chang GQ, Karatayev O, Davydova Z, Wortley K, Leibowitz SF. Glucose injection reduces neuropeptide $\mathrm{Y}$ and agouti-related protein expression in the arcuate nucleus: a possible physiological role in eating behavior. Brain Res Mol Brain Res. 2005; 135:69-80. [PubMed: 15857670]

DiLeone RJ, Georgescu D, Nestler EJ. Lateral hypothalamic neuropeptides in reward and drug addiction. Life Sci. 2003; 73:759-768. [PubMed: 12801597]

Dores RM, Jain M, Akil H. Characterization of the forms of betaendorphin and alpha-MSH in the caudal medulla of the rat and guinea pig. Brain Res. 1986; 377:251-260. [PubMed: 3015349]

Doron R, Fridman L, Yadid G. Dopamine-2 receptors in the arcuate nucleus modulate cocaine-seeking behavior. Neuroreport. 2006; 17:1633-1636. [PubMed: 17001283]

Dube D, Lissitzky JC, Leclerc R, Pelletier G. Localization of alpha-melanocyte-stimulating hormone in rat brain and pituitary. Endocrinology. 1978; 102:1283-1291. [PubMed: 744026] 
Dunbar J, Lapanowski K, Barnes M, Rafols J. Hypothalamic agouti-related protein immunoreactivity in food-restricted, obese, and insulin-treated animals: evidence for glia cell localization. Exp Neurol. 2005; 191:184-192. [PubMed: 15589525]

Ercil NE, Galici R, Kesterson RA. HS014, a selective melanocortin-4 (MC4) receptor antagonist, modulates the behavioral effects of morphine in mice. Psychopharmacology (Berl). 2005; 180:279-285. [PubMed: 15719225]

Fetissov SO, Bergstrom U, Johansen JE, Hokfelt T, Schalling M, Ranscht B. Alterations of arcuate nucleus neuropeptidergic development in contactin-deficient mice: comparison with anorexia and food-deprived mice. Eur J Neurosci. 2005; 22:3217-3228. [PubMed: 16367788]

Franklin, KBJ.; Paxinos, G. The Mouse Brain in Stereotaxic Coordinates. Academic Press; San Diego, CA: 1997.

Froehlich JC, Li TK. Recent developments in alcoholism:opioid peptides. Recent Dev Alcohol. 1993; 11:187-205. [PubMed: 7901877]

Gianoulakis C. Influence of the endogenous opioid sytem on high alcohol consumption and genetic predisposition to alcoholism. J Psychiatry Neurosci. 2001; 26:304-318. [PubMed: 11590970]

Goudreau JL, Manzanares J, Lookingland KJ, Moore KE. 5HT2 receptors mediate the effects of stress on the activity of periventricular hypophysial dopaminergic neurons and the secretion of alphamelanocyte-stimulating hormone. J Pharmacol Exp Ther. 1993; 265:303-307. [PubMed: 8386238]

Hadley ME, Haskell-Luevano C. The proopiomelanocortin system. Ann NY Acad Sci. 1999; 885:121. [PubMed: 10816638]

Harris GC, Aston-Jones G. Arousal and reward: a dichotomy in orexin function. Trends Neurosci. 2006; 29:571-577. [PubMed: 16904760]

Hayes DM, Knapp DJ, Breese GR, Thiele TE. Comparison of basal neuropeptide Y and corticotropin releasing factor levels between the high ethanol drinking C57BL/6J and low ethanol drinking DBA/2J inbred mouse strains. Alcohol Clin Exp Res. 2005; 29:721-729. [PubMed: 15897715]

Homanics GE, Quinlan JJ, Firestone LL. Pharmacologic and behavioral responses of inbred C57BL/6J and strain 129/SvJ mouse lines. Pharmacol Biochem Behav. 1999; 63:21-26. [PubMed: 10340519]

Hunt GE, McGregor IS. Rewarding brain stimulation induces only sparse Fos-like immunoreactivity in dopaminergic neurons. Neuroscience. 1998; 83:501-515. [PubMed: 9460758]

Jacobowitz DM, O'Donohue TL. alpha-Melanocyte stimulating hormone: immunohistochemical identification and mapping in neurons of rat brain. PNAS. 1978; 75:6300-6304. [PubMed: 366617]

Kas MJ, Bruijnzeel AW, Haanstra JR, Wiegant VM, Adan RA. Differential regulation of agoutirelated protein and neuropeptide $\mathrm{Y}$ in hypothalamic neurons following a stressful event. $\mathrm{J} \mathrm{Mol}$ Endocrinol. 2005; 35::159-164. [PubMed: 16087729]

Kokare DM, Singru PS, Dandekar MP, Chopde CT, Subhedar NK. Involvement of alpha-melanocyte stimulating hormone (alpha-MSH) in differential ethanol exposure and withdrawal related depression in rat: neuro-anatomical-behavioral correlates. Brain Res. 2008; 1216:53-67. [PubMed: 18499089]

Koob GF. Alcoholism: allostasis and beyond. Alcohol Clin Exp Res. 2003:232-243. [PubMed: 12605072]

Lewis MJ, Rada P, Johnson DF, Avena NM, Leibowitz SF, Hoebel BG. Galanin and alcohol dependence: neurobehavioral research. Neuropeptides. 2005; 39:317-321. [PubMed: 15885773]

Lindblom J, Wikberg JES, Bergstrom L. Alcohol-preferring AA rats show a derangement in their central melanocortin signalling system. Pharm Biochem Behav. 2002; 72:491-496.

Liu J, Garza JC, Truong HV, Henschel J, Zhang W, Lu XY. The melanocortinergic pathway is rapidly recruited by emotional stress and contributes to stress-induced anorexia and anxiety-like behavior. Endocrinology. 2007; 148:5531-5540. [PubMed: 17673512]

Marsh DJ, Hollopeter G, Huszar D, Laufer R, Yagaloff KA, Fisher SL, Burn P, Palmiter RD. Response of melanocortin-4 receptor-deficient mice to anorectic and orexigenic peptides. Nat Gen. 1999; 21:119-122. 
Navarro M, Cubero I, Chen AS, Chen HY, Knapp DJ, Breese GR, Marsh DJ, Thiele TE. Effects of melanocortin receptor activation and blockade on ethanol intake: a possible role for the melanocortin-4 receptor. Alcohol Clin Exp Res. 2005; 29:949-957. [PubMed: 15976520]

Navarro M, Cubero I, Knapp DJ, Breese GR, Thiele TE. Decreased immunoreactivity of the melanocortin neuropeptide alpha-melanocyte-stimulating hormone (alpha-MSH) after chronic ethanol exposure in Sprague-Dawley rats. Alcohol Clin Exp Res. 2008; 32:266-276. [PubMed: 18162070]

Navarro M, Cubero I, Knapp DJ, Thiele TE. MTII-induced reduction of voluntary ethanol drinking is blocked by pretreatment with AgRP-(83-132). Neuropeptides. 2003; 37:338-344. [PubMed: 14698676]

Navarro M, Cubero I, Ko L, Thiele TE. Deletion of agouti-related protein blunts ethanol selfadministration and binge-like drinking in mice. Genes Brain Behav. 2009; 8:450-458. [PubMed: 19566712]

O'Donohue TL, Dorsa DM. The opiomelanotropinergic neuronal and endocrine systems. Peptides. 1982; 3:353-395. [PubMed: 6289277]

O'Donohue TL, Jacobowitz DM. Studies of alpha-MSH-containing nerves in the brain. Prog Biochem Pharmacol. 1980; 16:69-83. [PubMed: 7443730]

O'Donohue TL, Miller RL, Jacobowitz DM. Identification, characterization and stereotaxic mapping of intraneuronal alpha-melanocyte stimulating hormone-like immunoreactive peptides in discrete regions of the rat brain. Brain Res. 1979; 176:101-123. [PubMed: 385110]

Ploj K, Roman E, Kask A, Hyytia P, Schioth HB, Wikberg J, Nylander I. Effects of melanocortin receptor ligands on ethanol intake and opioid levels in alcohol-preferring AA rats. Brain Res Bull. 2002; 59:97-104. [PubMed: 12379439]

Pritchard LE, Turnbull AV, White A. Pro-opiomelanocortin processing in the hypothalamus: impact on melanocortin signalling and obesity. J Endocrinol. 2002; 172:411-421. [PubMed: 11874690]

Rasmussen DD, Boldt BM, Wilkinson CW, Mitton DR. Chronic daily ethanol and withdrawal: 3 . Forebrain pro-opiomelanocortin gene expression and implications for dependence, relapse, and deprivation effect. Alcohol Clin Exp Res. 2002; 26:535-546. [PubMed: 11981131]

Roda F, Pio J, Bianchi AL, Gestreau C. Effects of anesthetics on hypoglossal nerve discharge and cFos expression in brainstem hypoglossal premotor neurons. J Comp Neurol. 2004; 468:571-586. [PubMed: 14689487]

Sainsbury A, Cooney GJ, Herzog H. Hypothalamic regulation of energy homeostasis. Best Pract Res Clin Endocrinol Metab. 2002; 16:623-637. [PubMed: 12468411]

Scanlon MN, Lazar-Wesley E, Csikos T, Kunos G. Rat hypothalamic proopiomelanocortin messenger RNA is unaffected by adrenalectomy. Biochem Biophys Res Com. 1992; 186:418-425. [PubMed: 1632781]

Schneider ER, Rada P, Darby RD, Leibowitz SF, Hoebel BG. Orexigenic peptides and alcohol intake: differential effects of orexin, galanin, and ghrelin. Alcohol Clin Exp Res. 2007; 31:1858-1865. [PubMed: 17850217]

Shutter JR, Graham M, Kinsey AC, Scully S, Luthy R, Stark KL. Hypothalamic expression of ART, a novel gene related to agouti, is up-regulated in obese and diabetic mutant mice. Genes Dev. 1997; 11:593-602. [PubMed: 9119224]

Thiele TE, Cubero I, van Dijk G, Mediavilla C, Bernstein IL. Ethanol-induced c-Fos expression in catecholamine- and neuropeptide Y-producing neurons in rat brainstem. Alcohol Clin Exp Res. 2000; 24:802-809. [PubMed: 10888068]

Thiele TE, Roitman MF, Bernstein IL. c-Fos induction in rat brainstem in response to ethanol- and lithium chloride-induced conditioned taste aversions. Alcohol Clin Exp Res. 1996; 20:1023-1028. [PubMed: 8892522]

Thiele TE, Roitman MF, Bernstein IL. Learned tolerance to ethanol-induced c-Fos expression in rats. Behav Neurosci. 1998a; 112:193-198. [PubMed: 9517827]

Thiele TE, van Dijk G, Bernstein IL. Ethanol-induced c-Fos expression in rat lines selected for low and high alcohol consumption. Brain Res. 1997; 756:278-282. [PubMed: 9187343] 
Thiele TE, van Dijk G, Yagaloff KA, Fisher SL, Schwartz M, Burn P, Seeley RJ. Central infusion of melanocortin agonist MTII in rats: assessment of c-Fos expression and taste aversion. Am J Physiol. 1998b; 274(1 Pt 2):R248-R254. [PubMed: 9458925]

Tolle V, Low MJ. In vivo evidence for inverse agonism of Agouti-related peptide in the central nervous system of proopiomelanocortindeficient mice. Diabetes. 2008; 57:86-94. [PubMed: 17909095]

Wagner CG, McMahon CD, Marks DL, Daniel JA, Steele B, Sartin JL. A role for agouti-related protein in appetite regulation in a species with continuous nutrient delivery. Neuroendocrinology. 2004; 80:210-218. [PubMed: 15604600]

Weitemier AZ, Tsivkovskaia NO, Ryabinin AE. Urocortin 1 distribution in mouse brain is straindependent. Neuroscience. 2005; 132:729-740. [PubMed: 15837134]

Yamazoe M, Shiosaka S, Yagura A, Kawai Y, Shibasaki T, Ling N, Tohyama M. The distribution of alpha-melanocyte stimulating hormone (alpha-MSH) in the central nervous system of the rat: an immunohistochemical study. II. Lower brain stem. Peptides. 1984; 5:721-727. [PubMed: 6387647]

Zhou Y, Franck J, Spangler R, Maggos CE, Ho A, Kreek MJ. Reduced hypothalamic POMC and anterior pituitary CRF1 receptor mRNA levels after acute, but not chronic, daily "binge" intragastric alcohol administration. Alcohol Clin Exp Res. 2000; 24:1575-1582. [PubMed: 11045867]

Ziotopoulou M, Mantzoros CS, Hileman SM, Flier JS. Differential expression of hypothalamic neuropeptides in the early phase of diet-induced obesity in mice. Am J Physiol Endocrinol Metab. 2000; 279:E838-E845. [PubMed: 11001766] 


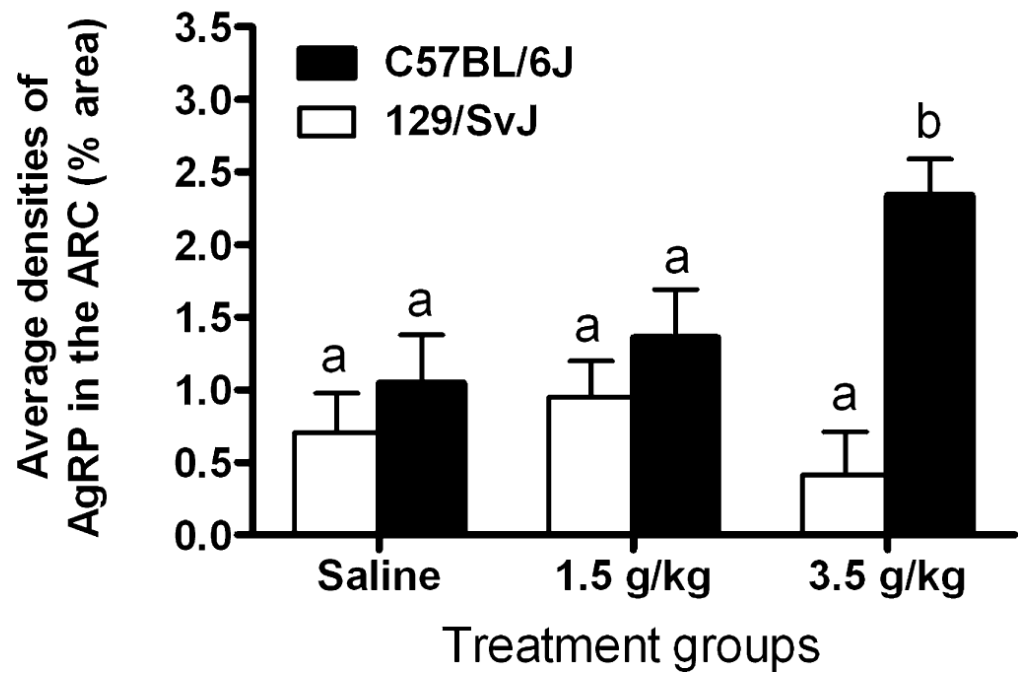

Fig. 1.

Quantification of Agouti-related protein immunoreactivity (AgRP) (\% area) in the arcuate nucleus of the hypothalamus (ARC). 129/SvJ and C57BL/6J mice were given intraperitoneal injection of isotonic saline or a $1.5 \mathrm{~g} / \mathrm{kg}$ or $3.5 \mathrm{~g} / \mathrm{kg}$ dose of ethanol, and brains were collected 2 hours after injections. Values are represented as mean \pm SEM. There are statistical differences between groups that do not share overlapping lettering (a or b; $p<$ 0.05 ). 


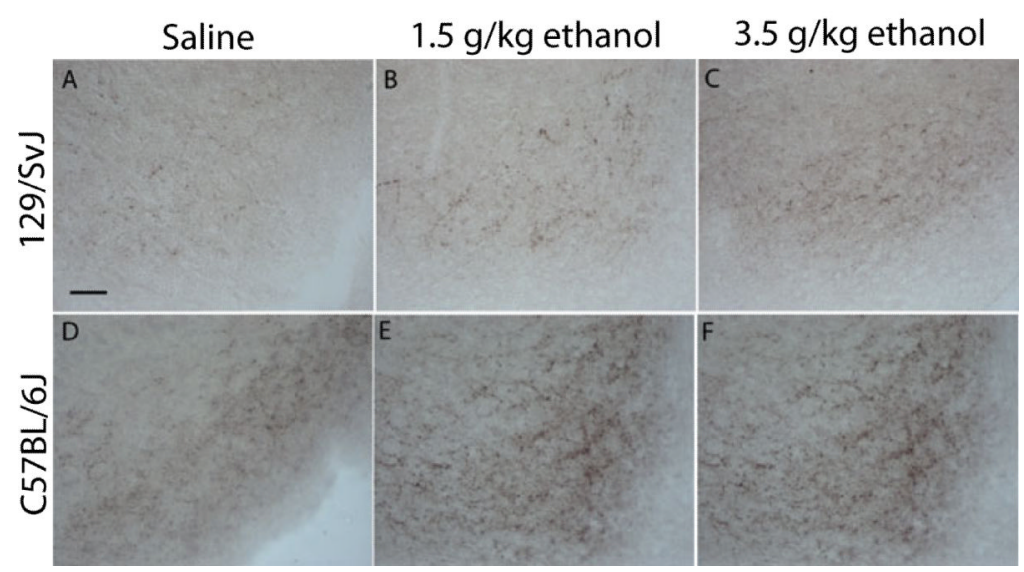

Fig. 2.

Representative photomicrographs of $40 \mathrm{~lm}$ coronal sections showing Agouti-related protein immunoreactivity through the arcuate nucleus of the hypothalamus (ARC) in 129/SvJ and $\mathrm{C} 57 \mathrm{BL} / 6 \mathrm{~J}$ mice that were given intraperitoneal injection of isotonic saline or a $1.5 \mathrm{~g} / \mathrm{kg}$ or $3.5 \mathrm{~g} / \mathrm{kg}$ dose of ethanol. Images were photographed at approximately $-1.7 \mathrm{~mm}$ relative to Bregma and quantified at a magnification of $40 \times$. Scale bar $=50 \mu \mathrm{m}$. 

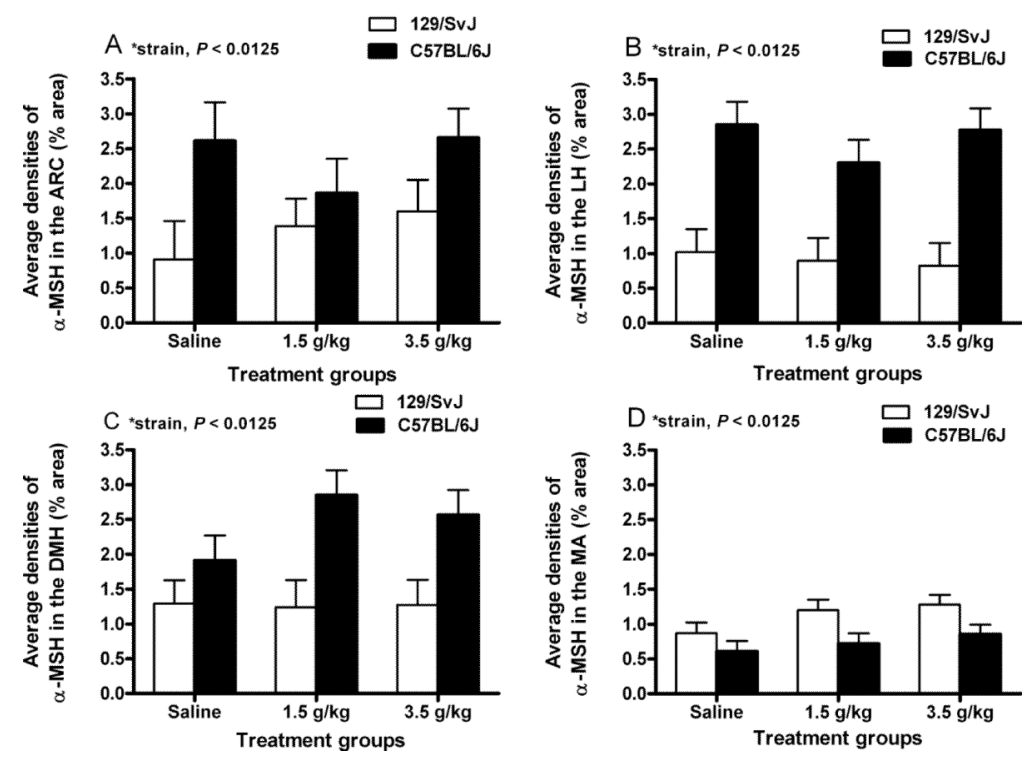

Fig. 3.

Quantification of $\alpha$-melanocyte stimulating hormone ( $\alpha-\mathrm{MSH})$ immunoreactivity (\% area) in the arcuate nucleus of the hypothalamus (ARC; $\mathbf{A}$ ), the lateral nucleus of the hypothalamus (LH; B), the dorsomedial nucleus of the hypothalamus (DMH; C), and the medial amygdala (MA; D). 129/SvJ and C57BL/6J mice were given intraperitoneal injection of isotonic saline or a $1.5 \mathrm{~g} / \mathrm{kg}$ or $3.5 \mathrm{~g} / \mathrm{kg}$ dose of ethanol, and brains were collected 2 hours after injections. Values are represented as mean \pm SEM. 


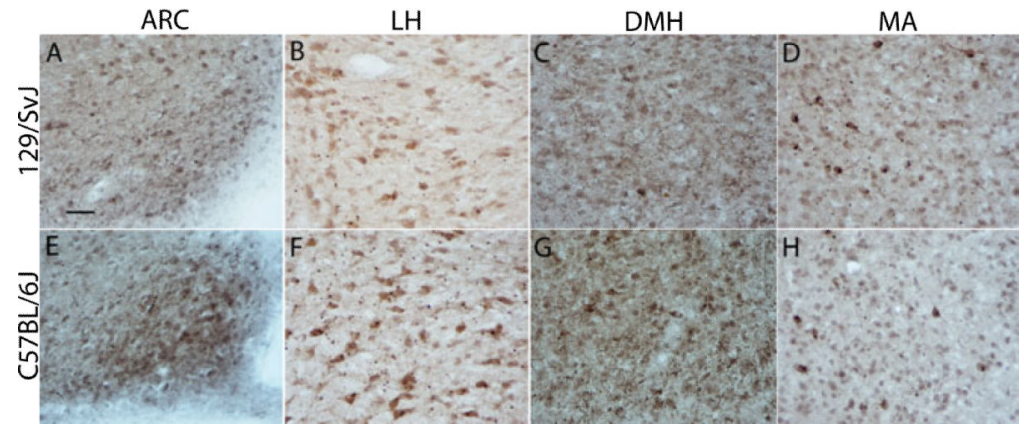

Fig. 4.

Representative photomicrographs of $40 \mu \mathrm{m}$ coronal sections showing $\alpha$-melanocyte stimulating hormone $(\alpha-\mathrm{MSH})$ immunoreactivity through the arcuate nucleus of the hypothalamus (ARC; $\mathbf{A}$ and $\mathbf{E}$ ), the lateral nucleus of the hypothalamus ( $\mathrm{LH} ; \mathbf{B}$ and $\mathbf{F})$, the dorsomedial nucleus of the hypothalamus (DMH; $\mathbf{C}$ and $\mathbf{G})$, and the medial amygdala (MA; $\mathbf{D}$ and $\mathbf{H})$ in saline treated mice. Sections were collected from 129/SvJ (A-D) and C57BL/6J (E-H)mice. Images were photographed and quantified at a magnification of $40 \times$. Relative to Bregma, photographs were taken at approximately $-1.7 \mathrm{~mm}$ (ARC and DMH) and -1.34 $\mathrm{mm}$ (LH and MA). Scale bar $=50 \mu \mathrm{m}$. 